\title{
Correction to: A serological survey of Toxoplasma gondii infection in sheep and goat from Benin, West-Africa
}

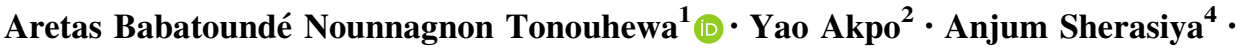 \\ Philippe Sessou $^{1}$ - Justin Mario Adinci ${ }^{1}$ - Gibert Luc Aplogan ${ }^{3}$. Issaka Youssao ${ }^{1}$. \\ Marc Napoleon Assogba ${ }^{1} \cdot$ Souaïbou Farougou ${ }^{1}$
}

Published online: 28 May 2019

(C) Indian Society for Parasitology 2019

\section{Correction to: J Parasit Dis \\ https://doi.org/10.1007/s12639-018-01076-1}

In the original publication of the article, one of the authors' name and affiliation is incorrect and the author has requested to correct it. The correct name and affiliation is mentioned below.

\section{Anjum Sherasiya}

Ex-Veterinary Officer, Department of Animal Husbandry, Gujarat State, Star, Gulshan Park, NH-8A, Chandrapur Road, Wankaner-363621, Dist. Morbi, Gujarat, India.

The original article has been corrected.

The original article can be found online at https://doi.org/10.1007/ s12639-018-01076-1.

Aretas Babatoundé Nounnagnon Tonouhewa

tonouhewaaretas@gmail.com

1 Communicable Disease Research Unit (URMaT), University of Abomey-Calavi, 01, P.O. Box 2009, Cotonou, Benin

2 Laboratory of Ecology, Health and Animal Production, Faculty of Agronomy, University of Parakou, P.O. Box 123, Parakou, Benin

3 Laboratory for Veterinary Diagnosis and Serosurveillance of Animal Diseases, Ministry of Agriculture, Livestock and Fisheries, Cotonou, Benin

4 Star, Gulshan Park, NH-8A, Chandrapur Road, Wankaner, Dist. Morbi, Gujarat 363621, India 